Arabiyat : Jurnal Pendidikan Bahasa Arab dan Kebahasaaraban

\title{
TRANSKULTURASI DALAM PENERJEMAHAN PRONOMINA PADA TERJEMAHAN ALQURAN BAHASA SUNDA
}

\author{
Syihabuddin \\ Universitas Pendidikan Indonesia Bandung, Indonesia \\ syibabuddin@upi.edu
}

\begin{abstract}
The pronouns of Arabic are different from the pronouns of Sundanese. Arabic pronouns have egalitarian and neutral meanings, while Sundanese pronouns reveal the dimensions of sociocultural and politeness. If the pronouns of the two languages are expressed in translation, how would linguistic devices respond to the transculturation between the two languages? To answer this question, the data were collected from the translation of the Arabic pronouns in the Qur'an Surah Ali 'Imran and used semantic analysis method to compare the lexical, contextual, and pragmatic meanings of the two languages. From 14 Arabic pronouns, only 9 pronouns were translated variably. The translation is capable of equally conveying the concept of quantity ('adad) in the recipient language through the affixation process, but has not been able to address the gender aspect. The translation also considered the interpersonal meaning and the relationship of the interlocutors. This is a form of transculturation from being neutral, egalitarian, and exclusive to become partial, inclusive, polite, and communicative.
\end{abstract}

Keywords: $\quad$ transculturation, pronouns, translation of the Qur'an

\begin{abstract}
Abstrak
Pronomina bahasa Arab memiliki makna yang egaliter dan netral, sedangkan pronomina bahasa Sunda mengungkapkan dimensi sosial-budaya dan kesantunan. Jika pronomina kedua bahasa itu diungkapkan dalam penerjemahan, bagaimanakah piranti linguistik merespon transkulturasi antara kedua bahasa itu? Pertanyaan ini mendorong peneliti untuk menjawabnya melalui penelitian terjemahan Al-Qur'an Miwah Tarjamahna Dina Basa Sunda. Untuk mencapai tujuan ini digunakan metode analisis semantik yang mengkomparasikan makna leksikal, kontekstual, dan makna pragmatik kedua bahasa. Data yang dikumpulkan berupa terjemahan kata ganti bahasa Arab dalam Alquran surah Ali 'Imran yang berjumlah 200 ayat. Dari 14 pronomina bahasa Arab, hanya ada 9 pronomina yang diterjemahkan dengan variatif. Terjemahan itu mampu mengekuivalensikan konsep jumlah ('adad) dalam bahasa penerima melalui proses afiksasi, tetapi belum mampu memenuhi aspek jender. Terjemahan itu pun mempertimbangkan makna interpersonal dan hubungan mitra tutur dengan memasukkan unsur budaya kesantunan ke dalam terjemahan. Inilah bentuk transkulturasi dari netral, egaliter, dan eksklusif menjadi memihak, inklusif, santun, dan komunikatif sebagai dampak dari penggunaan metode penerjemahan komunikatif.
\end{abstract}

Kata Kunci: transkulturasi, pronomina, terjemaban Alquran 


\section{Pendahuluan}

Islam adalah agama rahmat yang dibawa oleh Nabi Pembawa rahmat bagi semesta alam. Penutur bahasa Sunda pun diberi rahmat itu dan mereka juga berupaya untuk mendapatkannya. Upaya mereka diwujudkan dengan menerjemahkan Alquran ke dalam bahasa Sunda.

Menurut Rohmana dalam khazanah terjemahan Alquran bahasa Sunda terdapat beberapa karya. Pertama, Al-Amin: Al-Qur'an Tarjamab Sunda diterbitkan CV Diponegoro tahun 1971, karya K.H. Qamaruddin Shaleh, H.A.A. Dahlan, dan Yus Rusamsi. Kedua, Al-Munir: Al-Qur'an Tarjamah Basa Sunda diterbitkan Pustaka Fithri tahun 2005, karya H.M. Djawad Dahlan. Ketiga, Nur Hidayah: Saritilawah Basa Sunda, Al-Qur'an, diterbitkan Yayasan Nur Hidayah tahun 1994, karya H.R. Hidayat Surayalaga sebagai karya kreatif dalam bentuk pupuh, yaitu bentuk puisi Sunda yang terikat oleh pola rima dan jumlah suku kata pada tiap barisnya, yang biasanya dijadikan lirik tembang. ${ }^{1}$

Di samping terjemahan, ada pula karya dalam bentuk tafsir, di antaranya Ayat Suci Lenyepaneun, karya Moh. E. Hasim, diterbitkan Pustaka tahun 1984. Tafsir yang terdiri atas 30 jilid ini merupakan tafsir paling lengkap dalam bahasa Sunda. Pada 1960 terbit pula Nurul-Bajan: Tafsir Qur'an Basa Sunda karya H. Mhd. Romli dan H.N.S. Midjaja, yang diterbitkan N.V. Perboe. Jauh sebelum itu, yakni tahun 1937 terbit Tafsir Al-Foerqan Basa Sunda, karya A. Hassan terdiri dari 3 jilid.

Selain itu, kegiatan penafsiran pun dilakukan secara kelompok dan difasilitasi oleh pemerintah provinsi Jawa Barat sejak tahun 1987. Upaya ini dilakukan secara terus-menerus hingga terbit Al-Qur'an Miwah Tarjamahna Dina Basa Sunda pada tahun 2016.

Tentu saja karya-karya di atas berkontribusi bagi peningkatan pengetahuan, pemahaman, dan kualitas keberagamaan masyarakat Sunda yang memiliki akses terhadap karya-karya di atas sebagai teks suci (boly texts). Menurut Long, kesucian sebuah teks tergantung kepada manusia yang menggunakannya, status yang diberikan pada teks itu, dan kepentingan teks tersebut bagi mereka. Kebudayaan tertentu memandang sebuah teks itu suci dan sakral, tetapi kebudayaan lain memandangnya tidak demikian. Apapun yang disebut teks suci, kehadirannya dalam berbagai budaya dan agama telah berjasa dalam mendorong manusia untuk menerjemahkannya. Untuk mengetahui bagaimana penerjemahan teks suci dilakukan, bagaimana kualitasnya, dan bagaimana manfaatnya bagi pembaca, maka para ahli dan akademisi meneliti berbagai jenis teks suci. ${ }^{2}$

Di antara teks suci yang diteliti ialah terjemahan majaz, mursal pada tafsir karya Moh. E. Hasim dan Al-Qur'an Miwah Tarjamabna Dina Basa Sunda yang diterbitkan

1Jajang A. Rohmana, "Ideologisasi Tafsir Lokal Berbahasa Sunda: Kepentingan Islam-Modernis dalam Tafsir Nurul-Bajan dan Ayat Suci Lenyepaneun. "Journal of Qur'an and Hadith Studies - Vol. 2, No. 1, . (2013), 125-154. Ltd, 2005).

${ }^{2}$ Lynne Long (editor), Translation and Religion: Holy Unstranslatable (Canada: Multilingual Matter 
Pemerintah Provinsi Jawa Barat. Teks itu diteliti oleh Hermawan yang menyimpulkan bahwa dalam terjemahan Hasim terdapat 45,71\% terjemah majâz mursal yang sesuai dengan dasar-dasar balâghah dan pendapat mufassir dan 54,29\% terjemahan yang tidak sesuai. Adapun dalam terjemahan Pemda Jabar terdapat $40 \%$ terjemahan yang sesuai dengan dasar-dasar balâghah dan pendapat mufassir dan 60\% terjemah yang tidak sesuai. Ketidaksesuaian tersebut memengaruhi kualitas terjemahan, menimbulkan hilangnya makna bahasa sumber, dan tidak sampainya amanat bahasa sumber di dalam bahasa penerima. ${ }^{3}$

Hilangnya makna dalam terjemahan juga dikemukakan oleh Abdulaal yang meneliti semantic lost dalam terjemahan surah al-Wâqiah. Istilah semantic lost merujuk pada kelebihan, kekurangan, dan kesalahan dalam penerjemahan bahasa sumber di dalam bahasa sasaran. Dia menyimpulkan bahwa kehilangan makna sebagian merupakan gejala yang paling banyak terjadi dalam terjemahan surah al-Wâqiah, bahkan dijumpai hilangnya makna keseluruhan, terutama pada istilah atau kosakata kebudayaan. ${ }^{4}$

Hilangnya makna kosa kata kebudayaan tidak hanya terjadi pada teks suci, tetapi terjadi juga pada teks yang berkaitan dengan perdagangan dan bisnis. Al-Rajhi, Barlett, Altman, dan Su meneliti perkembangan tingkat penyesuaian topik-topik kebudayaan Arab dengan berbagai kebudayaan lainnya dalam wacana bisnis, politik, dan sastra. Penelitian ini menyimpulkan bahwa ada lima faktor yang memengaruhi tingkat pemahaman pembaca atau pendengar terhadap kosa kata kebudayaan dalam kegiatan bisnis dan politik yaitu jenis pekerjaan, kepentingan penulis, status mitra tutur, interaksi sosial, dan hal-hal yang berkaitan dengan kepentingan umum. ${ }^{5}$

Pemahaman terhadap kosa kata kebudayaan tersebut tidaklah utuh. Pada umumnya pemahaman itu bersifat parsial, bahkan ada kosakata kebudayaan yang benar-benar tidak ada padanannya. Blenkinsopp dan Pajouh menelaah unsur-unsur kebudayaan yang hilang dalam penerjemahan pada kegiatan bisnis internasional. Peneliti mewawancara sejumlah penerjemah profesional dalam kegiatan bisnis tentang bagaimana strategi mereka dalam menangani istilah yang tidak dapat diterjemahkan. Pada umumnya, strategi yang mereka gunakan ialah menghindari penerjemahan dan mementingkan konteks serta hubungan personal guna memahami komunikasi lintas budaya. ${ }^{6}$

${ }^{3}$ Acep Hermawan, Penerjemahan Majaz Mursal dalam Alquran Terjemah Sunda Karya M.E. Hasim dan Pemda Jabar ( Disertasi. Bandung: UIN Sunan Gunung Jati, 2005), ....

${ }^{4}$ Noureldin Mohammed Abdelaal, Semantic Loss in the Holy Qur'an Translation With Special Reference to Surah Al-Waqiah (Chapter of The Event Inevitable). SAGE and Open Access, 2015.

${ }^{5}$ Ibrahim Al-Rajhi, Dean Bartlett, Yochanan Altman. Research Note: The Development of an Arabic cross-cultural adjusment scale. Cross Cultural Management, Vol.20. No.3, (2013), pp.449-463; Yujie Su. "A Corpus-based Contrastive Analysis of First Personal Deixis". Journal of Language Teaching and Research, Vol. 1, No. 3, 2010, pp. 231-234.

'John Blenkinsopp, Maryam Shademan Pajouh, "Lost in translation? Culture, language and the role of the translator in international business". Critical Perspective on international business, Vol.6, No. 1, 2010, 38-52. 
Giovanni mengupas kaitan antara penerjemahan, kebudayaan, dan media massa. Menurutnya, penerjemahan bukan hanya sebuah jendela yang dibuka untuk melihat dunia lain atau penjelasan bersifat basa-basi, tetapi terjemahan merupakan saluran yang digelar dan dijelaskan oleh penerjemah tanpa rasa sungkan, sehingga budaya asing yang terkandung dalam bahasa sumber dapat masuk ke dalam budaya asli yang ada dalam bahasa target. Kegiatan membuka saluran dan jendela serta memberikan penjelasan kepada pemilik bahasa target menimbulkan gejala yang disebut transkulturasi. ${ }^{7}$

Menurut Lull, transkultursi merujuk pada proses peralihan dan interaksi serta saling mempengaruhi di antara bentuk-bentuk atau latar budaya yang mengikuti perjalanan waktu dan ruang, sehingga terbentuklah kebudayaan baru. Piranti yang membentuk kebudayaan baru ini ialah media masa. Media adalah sarana yang bekerja dengan mengeksploitasi bahasa secara penuh melalui penerjemahan berbagai bentuk kebudayaan. $^{8}$

Proses transkulturasi tersebut ditunjukkan pula dalam penelitian Babaee and Yahya, Beypi dan Biswas, dan Zsok yang menegaskan bahwa penerjemahan bukan hanya transformasi bentuk dari satu bahasa ke bahasa lain, tetapi merupakan pengalihan seluruh pesan teks bahasa sumber, termasuk di dalamnya budaya, kehidupan sosial, dan sejarah dalam bentuk yang akrab dan bermakna bagi para pengguna bahasa target. Dalam konteks ini, penerjemah itu seperti utusan tuhan yang harus memahami pesan secara penuh, kemudian mengalihkannya kepada bahasa target dengan cara yang mudah dipahami oleh pembaca. Oleh karena itu, penerjemah perlu memahami budaya bahasa sumber dan bahasa target. ${ }^{9}$

Namun, penjelasan budaya oleh "rasul" itu tidak dapat diwakili oleh mesin penerjemahan. Hal ini dilaporkan oleh Aziz dan Hendr yang menelaah mesin penerjemahan google dalam menerjemahkan bahasa Arab klasik. Salah satu kesimpulannya ialah bahwa penerjemahan bahasa Arab klasik memerlukan analisis yang lebih canggih agar dapat masuk ke dalam tataran semantik dan pragmatik agar dapat mengalihkan makna. Salah satu makna yang tidak dapat diungkapkan dalam bahasa target ialah makna yang terkandung dalam kosa kata budaya. ${ }^{10}$

Karena itu, sangatlah beralasan jika Nelson berpendapat bahwa penerjemahan merupakan praktik pemakaian budaya dan bahasa. Pada penerjemahan dilakukan pembentukan berbagai jenis kebudayaan asing yang dapat dikonstruksi oleh para

${ }^{7}$ Elena Di Giovanni, "Translation, Culture, and The Media". European Journal of English Studies, Vol. 12, No.2, 2013, pp.123-131.

8James Lull, Media, Communication, Culture (New York: Columbia University, 2000).

${ }^{9}$ Ruzbeh Babaee, Wan Roselezam Bt Wan Yahya, "Creativity, Culture and Translation", English Language Teaching; Vol. 7, No. 6, 2014, p. 14-18.; Serdihun Beypi and Shiva Biswas, "Language, Culture, and Translation of the Karbi: A Brief Study". International Journal of Social Science and Humanity, Vol. 2, No. 6, 2012, pp. 8-15.; dan Izzabela Zsok, "The Culture of Translation: Texts and Practices". Philobiblon Vol. 17, No. 1, 2012 pp. 307-312.

${ }^{10}$ Mohammed Aziz and Ahmed Hendr, "Tranlation of Classical Arabic Language To English". Journal of Applied Sciences, Vol. 12 (8), 2012. pp. 781-786. 
pengguna bahasa penerima. Penerjemahan memiliki peran yang dimainkan untuk menjamin hubungan yang saling menguntungkan antara dua bahasa dan budaya yang berbeda. Cara yang dilakukan penerjemah ialah menggunakan teknik domestikasi, yaitu penerjemahan dengan menjadikan unsur budaya atau konsep internasional menjadi lokal. Penerjemah merupakan mediator antarkebudayaan dan sistem nilai pada kedua kebudayaan itu. Penerjemah memiliki peran yang sangat penting. Peran ini membuat posisinya yang subjektif dalam mengalihkan bahasa dan budaya. ${ }^{11}$

Kenyataan di atas sejalan dengan konsep penerjemahan sebagai kegiatan komunikasi yang melibatkan bahasa sumber dan bahasa penerima. Penerjemah berperan sebagai komunikator sekaligus mediator yang menjembatani pengalihan informasi dari penulis teks sumber kepada pembaca teks target. Peran ini menuntut penerjemah memiliki suatu strategi dalam menangani perbedaan dua bahasa dalam rangka menghadirkan ekuivalensi, baik pada tataran bahasa maupun tataran budaya. Karena itu, Newmark menjelaskan 10 aspek yang terlibat dalam proses penerjemahan sebuah teks. Kesepuluh arah itu ialah penulis bahasa sumber, norma yang berlaku pada bahasa penerima, budaya bahasa sumber, tradisi dan lingkungan bahasa sumber, tingkat literasi penutur bahasa target, norma bahasa target, budaya bahasa target, tradisi dan lingkungan bahaa target, penerjemah, dan kebenaran. Kesepuluh aspek tersebut jalin-menjalin dalam mempengaruhi kognisi penerjemah dalam menentukan metode dan teknik penerjemahan yang akan digunakan dalam mengalihbahasakan dan melakukan penyesuaian dari teks sumber ke dalam teks terjemahan. ${ }^{12}$

Menurut al-Farisi penyesuaian yang dilakukan penerjemah, baik berupa penambahan ataupun pengurangan, sejatinya harus mempertimbangan aspek kebenaran demi menghasilkan terjemahan yang akurat. Bagi setiap penerjemah, menjunjung tinggi kebenaran merupakan keniscayaan. Setiap bentuk pergeseran, misalnya pada tataran kaidah bahasa sumber dan bahasa penerima, sah-sah saja dilakukan sepanjang tidak menimbulkan terjadinya perubahan kebenaran. ${ }^{13}$

Karena penerjemahan itu merupakan proses kreatif, tentu penerjemah memiliki peluang untuk berimprovisasi dan berkreasi dalam proses penerjemahan. Hal ini didukung oleh Machali yang mengatakan bahwa intervensi penerjemah dalam proses penerjemahan sangat mungkin dilakukan karena beberapa alasan. Pertama, proses penerjemahan merupakan penerjemahan manusia (buman translation), bukan penerjemahan mesin (machine translation). Kedua, bahasa bukan merupakan "jaket pengaman" yang membelenggu penerjemah untuk memilih satu bentuk tertentu saja.

${ }^{11}$ Brian Nelson,"'Translating Culture, Cultures of Translation", Journal of Intercultural Studies, Vol 28, No.4, 2007, pp. 361-365; Mohammad Qasem Al-Hamad, "The Translatability Of Euphemism In The Holy Quran”. European Scientific Journal January 2013 edition vol.9, No.2.

${ }^{12}$ Peter Newmark, A Textbook of Translation (United Kingdom: Prentice Hall International, 1988); Ibrahim I.I. Najjar1. "A Contrastive Analysis of the Translation of Irony in the Holy Qur'an: The Translations of Mualawi Sher Ali and Yusuf Ali". American Research Journal of English and Literature. Volume 1, Issue 5, 2015, p 27.

${ }^{13}$ Muhammad Zaka Al Farisi, Analisis Terjemahan Ayat-ayat Imperatif Alquran (Telaah Komparatif Terjemah Depag dan Terjemah UMT) (Disertasi. Bandung: Sekolah Pascasarjana UPI, 2016). 
Dan ketiga, setiap penerjemah memiliki keunikan yang turut mewarnai dinamika yang terjadi dalam proses penerjemahan.

Berbagai strategi, intervensi, dan proses kreatif yang dilakukan penerjemahan berpengaruh signifikan terhadap bahasa target. Mat menelaah penerjemahan bahasa Arab ke bahasa Melayu. Dia menegaskan bahwa praktik penerjemahan memengaruhi pemakaian bahasa nasional. Hal ini sejalan dengan kehendak untuk memelihara bahasa nasional. Penerjemahan membantu bahasa lokal untuk berinteraksi dengan bahasa internasional dalam hal modal, budaya, dan ekonomi. Penerjemahan dapat memepertahankan budaya dan tradisi yang melekat pada bahasa sebagai identitas nasional atau lokal. Penerjemahan merupakan proses pemerolehan bahasa yang perlu dipertimbangkan.

Paparan di atas menunjukkan bahwa bahasa dan budaya bahasa sumber itu memengaruhi bahasa dan budaya bahasa target, demikian pula sebaliknya. Penelitian yang banyak dilakukan selama ini berkenaan dengan pengaruh bahasa dan budaya bahasa sumber terhadap bahasa dan budaya bahasa target. Memang alur pikir itulah yang logis, yaitu sumber memengaruhi target, bukan target yang memengaruhi sumber. Namun, dalam realitas ditemukan bahwa budaya bahasa target pun dapat memengaruhi budaya bahasa sumber. Hal ini tampak pada buku Al-Qur'an Miwah Tarjamahna Dina Basa Sunda yang diterbitkan tahun 2016 oleh Pemerintah Provinsi Jawa Barat, terutama dalam penerjemahan pronomina persona bahasa Arab yang berjumlah 14 buah.

Sehubungan dengan realitas tersebut muncullah pertanyaan, apakah penerjemahan pronomina persona bahasa Arab (ayat Alquran) ke dalam bahasa Sunda itu menimbulkan fenomena transkulturasi yang disebabkan perbedaan konsep jumlah, jender, dan unsur budaya di antara kedua bahasa itu? Bagaimana pengaruh metode penerjemahan yang mementingkan keterpahaman pembaca bahasa target? Bagaimanakah interaksi, transformasi, dan transkulturasi yang terjadi antara budaya Arab-Islam dengan budaya Sunda-Islam?

\section{Metode Penelitian}

Untuk menjawab pertanyaan di atas dilakukanlah penelitian dengan menggunakan metode analisis semantik makna leksikal, makna kontekstual, dan makna pragmatik pada terjemahan 14 pronomina bahasa Arab dalam pada Al-Qur'an Miwah Tarjamahna Dina Basa Sunda. Dari buku itu dipilih terjemahan surah Ali Imran yang berjumlah 200 ayat.

Data dikumpulkan dengan menggunakan format pengumpul data yang memuat informasi tentang teks sumber, terjemahan, nomor ayat, unsur 'adad, unsur jender, ragam bahasa, hubungan penutur dan mitra tutur, dan transkulturasi. Kemudian terjemahan seluruh pronomina tersebut dianalisis secara komparatif dengan mempertimbangan perbedaan, persamaan, dan perubahan di antara keduanya.

Analisis di atas menghasilkan sejumlah temuan yang disajikan dalam tabel. Karena hasil analisis itu sangat banyak, yaitu 24 halaman, maka dilakukan pemilahan ke 
dalam 9 tabel terjemahan pronomina. Karena tabel analisis ini pun dipandang masih terlalu banyak, maka diringkaskan ke satu tabel sebagai temuan penelitian. Kemudian temuan tersebut dibahas pada bagian khusus, yaitu bagian temuan dan pembahasa.

Untuk melihat perbedaan dan persamaan antara pronomina persona bahasa Sunda dengan bahasa Arab digunakanlah kriteria atau konsep yang disusun oleh Sudaryat seperti berikut. Pronomina persona yang disajikan di sini hanyalah yang diduga kuat bertalian dengan masalah penelitian.

\section{Tabel 1}

Kriteria Konsep Pronomina Persona

\begin{tabular}{|c|c|c|c|c|c|c|c|}
\hline \multirow{2}{*}{ Pronomina $\mathrm{O} 1$} & \multicolumn{2}{|c|}{ Jumlah } & \multicolumn{3}{|c|}{ Ragam } & \multicolumn{2}{|c|}{ Partisipan } \\
\hline & Tunggal & Jamak & Halus & Sedang & Kasar & Penutur & Mitra \\
\hline Abdi & $\mathrm{V}$ & - & $\mathrm{V}$ & - & - & $\left.\mathrm{R}^{*}\right)$ & $\left.\mathrm{T}^{*}\right)$ \\
\hline Abdi sadaya & - & - & V & - & - & $\mathrm{R}$ & $\mathrm{T}$ \\
\hline Kuala & V & - & - & V & - & $\mathrm{T}$ & $\mathrm{R}$ \\
\hline Urang & $\mathrm{V}$ & - & - & V & - & $\mathrm{S} *)$ & S \\
\hline Urang sarerea & & V & - & V & - & $\mathrm{S} *)$ & S \\
\hline \multicolumn{8}{|l|}{ Pronomina $\mathrm{O} 2$} \\
\hline Anjeun & $\mathrm{V}$ & - & - & V & - & $\mathrm{S} *)$ & S \\
\hline Aranjeun & - & V & - & V & - & $\mathrm{S} *)$ & S \\
\hline Maneh & V & - & - & V & - & $\mathrm{T}$ & $\mathrm{R}$ \\
\hline Maraneh & - & V & - & V & - & $\mathrm{T}$ & $\mathrm{R}$ \\
\hline Hidep & V & - & V & - & - & $\mathrm{T}$ & $\mathrm{R}$ \\
\hline Salira & V & - & V & - & - & $\mathrm{R}$ & $\mathrm{T}$ \\
\hline \multicolumn{8}{|l|}{ Pronomina $\mathrm{O} 2$} \\
\hline Anjeunna & $\mathrm{V}$ & - & - & $\mathrm{V}$ & - & $\left.\mathrm{S}^{*}\right)$ & S \\
\hline Aranjeunna & - & $\mathrm{V}$ & - & $\mathrm{V}$ & - & $\mathrm{S} *)$ & S \\
\hline Manehna & $\mathrm{V}$ & - & - & V & - & $\mathrm{T}$ & $\mathrm{R}$ \\
\hline Maranehna & - & V & - & V & - & $\mathrm{T}$ & $\mathrm{R}$ \\
\hline Mantenna & V & - & $\mathrm{V}$ & - & - & $\mathrm{R}$ & $\mathrm{T}$ \\
\hline
\end{tabular}

*) Catatan

$\mathrm{T}=$ Tinggi $\mid \mathrm{R}=$ Rendah $\mid \mathrm{S}=$ Sederajat antara penutur dan mitra tutur

14 Yayat Sudaryat, Pronomina Persona dalam Babasa Sunda (FPBS: Bandung, 2016). Lihat juga Tajudin Nur, "Analisis Kontrastif dalam Studi Bahasa”, Arabi: Journal of Arabic Studies, Vol. 1 No. 2, 2016, 64-74. 


\section{Temuan dan Pembahasan}

Setelah peneliti menganalisis data dalam format khusus yang membandingkan aspek jumlah ('adad), jender, dan variasi terjemahan pronomina dilihat dari partisipan yang terlibat dalam komunikasi di dalam surah Ali 'Imran, maka berikut disampaikan hasilnya dalam bentuk tabel.

Tabel 2

Temuan Penelitian

\begin{tabular}{|c|c|c|c|c|c|}
\hline No. & Arab & Sunda & Makna Arab & Makna Sunda & Transkulturasi \\
\hline \multirow[t]{9}{*}{1.} & \multirow[t]{9}{*}{ Huwa } & \multirow[t]{3}{*}{ Mantenna } & Dia seorang & Dia seorang & Jumlah terpenuhi \\
\hline & & & Laki-laki & laki-laki/wanita & Tidak terpenuhi \\
\hline & & & Netral & Halus & $\mathrm{R} \rightarrow \mathrm{T}$ \\
\hline & & \multirow[t]{3}{*}{ Anjeunna } & Dia seorang & Dia seorang & Terpenuhi \\
\hline & & & Laki-laki & laki-laki/wanita & Jumlah terpenuhi \\
\hline & & & Netral & Halus & $\mathrm{S} \rightarrow \mathrm{S}$ \\
\hline & & \multirow[t]{3}{*}{ Manehna } & Dia seorang & Dia seorang & Jumlah terpenuhi \\
\hline & & & Laki-laki & laki-laki/wanita & Tidak terpenuhi \\
\hline & & & Netral & Sedang & $\mathrm{T} \rightarrow \mathrm{R}$ \\
\hline \multirow[t]{6}{*}{2.} & \multirow[t]{6}{*}{ Hum } & \multirow[t]{3}{*}{ Maranehna } & Mereka & Mereka & Jumlah terpenuhi \\
\hline & & & Laki-laki & Laki-laki/wanita & Jender tidak terpenuhi \\
\hline & & & Netral & Sedang & $\mathrm{T} \rightarrow \mathrm{R}$ \\
\hline & & \multirow[t]{3}{*}{ Aranjeunna } & Mereka & Mereka & Jumlah terpenuhi \\
\hline & & & Laki-laki & Laki-laki/wanita & Jender tidak terpenuhi \\
\hline & & & Netral & Halus & $\mathrm{S} \rightarrow \mathrm{S}$ \\
\hline \multirow[t]{3}{*}{3.} & \multirow[t]{3}{*}{ Hiya } & \multirow[t]{3}{*}{ Manehna } & Dia seorang & Dia seorang & Jumlah terpenuhi \\
\hline & & & Perempuan & laki-laki/wanita & Tidak terpenuhi \\
\hline & & & Netral & Sedang & $\mathrm{S} \rightarrow \mathrm{S}$ \\
\hline 4. & Hunna & $\begin{array}{l}\text { Nya eta } \\
\text { pisan }\end{array}$ & $\begin{array}{l}\text { Mereka } \\
\text { perempuan } \\
\text { jamak }\end{array}$ & $\begin{array}{l}\text { Tidak merujuk } \\
\text { ke nama diri }\end{array}$ & $\begin{array}{l}\text { Tidak terjadi } \\
\text { Transkulturasi }\end{array}$ \\
\hline \multirow[t]{6}{*}{5.} & \multirow[t]{6}{*}{ Anta } & \multirow[t]{3}{*}{ Hidep } & Kamu seorang & Kamu seorang & Jumlah terpenuhi \\
\hline & & & Laki-laki & Laki-laki/wanita & Tidak terpenuhi \\
\hline & & & Netral & Sedang & $\mathrm{T} \rightarrow \mathrm{R}$ \\
\hline & & \multirow[t]{3}{*}{ Gusti } & Kamu seorang & Nama Tuhan & Jumlah terpenuhi \\
\hline & & & Mudzakar & Netral & Terpenuhi \\
\hline & & & Netral & Halus & $\mathrm{R} \rightarrow \mathrm{T}$ \\
\hline \multirow[t]{3}{*}{6.} & \multirow[t]{3}{*}{ Antum } & \multirow[t]{3}{*}{ Aranjeun } & Kalian & Kalian & Jumlah terpenuhi \\
\hline & & & Laki-laki & Laki-laki/wanita & Jender tak terpenuhi \\
\hline & & & Netral & Ragam halus & $\mathrm{S} \rightarrow \mathrm{S}$ \\
\hline \multirow[t]{3}{*}{7.} & \multirow[t]{3}{*}{ Anti } & \multirow[t]{3}{*}{ Hidep } & Kamu & Kamu & Jumlah terpenuhi \\
\hline & & & Perempuan & Laki-laki/wanita & Jender tak terpenuhi \\
\hline & & & Netral & Sedang & $\mathrm{T} \rightarrow \mathrm{R}$ \\
\hline \multirow[t]{3}{*}{8.} & \multirow[t]{3}{*}{ Ana } & \multirow[t]{3}{*}{ Kaula } & Saya & Saya & Jumlah terpenuhi \\
\hline & & & $\begin{array}{l}\text { Laki- } \\
\text { laki/wanita }\end{array}$ & Laki-laki/wanita & Jender terpenuhi \\
\hline & & & Netral & Sedang & $\mathrm{T} \rightarrow \mathrm{R}$ \\
\hline
\end{tabular}


Arabiyât Jurnal Pendidikan Bahasa Arab dan Kebahasaaraban, 5 (1), 2018

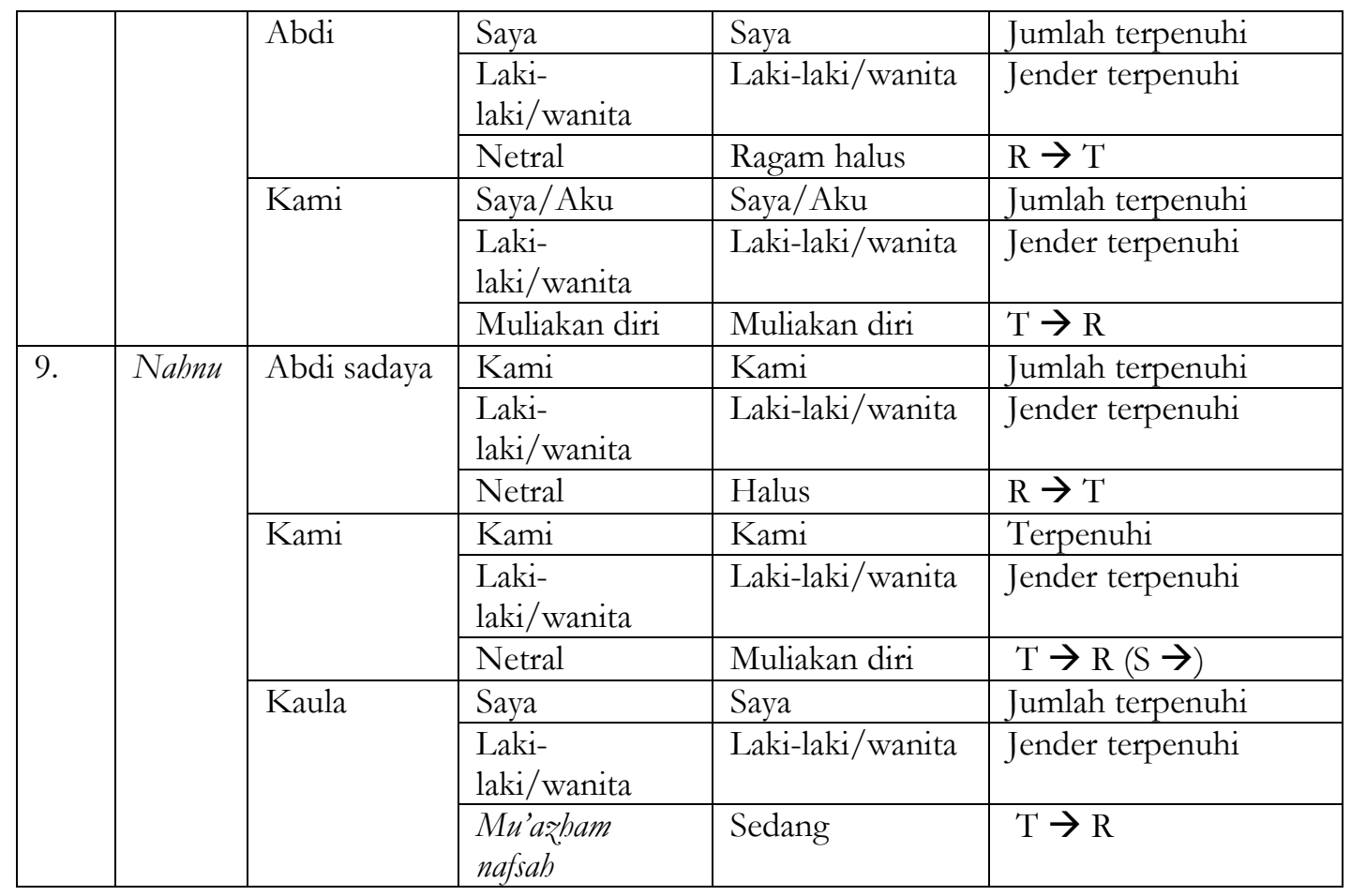

Tabel di atas memperlihatkan bahwa dari 14 dhamîr yang terdapat dalam bahasa Arab, hanya ada 9 dhamîr yang ada dalam data surah Ali Imran. Dhamîr yang diterjemahkan meliputi buwa, bum, hiya, bunna, anta, antum, anti, antunna, ana, nabnu. Dhamîr yang tidak terdapat dalam surah Ali 'Imran ialah buma (mudzakar), buma (mu 'annats), antuma (mudzakar), antuma (mu annats). Hal ini menunjukkan bahwa pada umumnya Alquran menceritakan individu, banyak orang, dan orang perorang. Dalam Alquran jarang digunakan dhamîr mutsanna kecuali pada cerita yang melibatkan dua orang, seperti cerita tentang Nabi Adam dan Hawa, Nabi Musa dan Nabi Harun, dua orang bersaudara, dan konteks lain yang menceritakan dua manusia.

Penerjemahan 9 dhamîr tersebut dilakukan secara variatif. Artinya, sebuah dhamîr diterjemahkan ke dalam lebih dari satu varian. Dhamir huwa, misalnya, diterjemahkan ke dalam beberapa varian, yaitu Mantenna, -Na, Manebna, -na, dan anjeunna. Hum diterjemahkan dengan maraneh, maranehna, aranjeun, aranjeunna. Hal ini menunjukkan bahwa penerjemah memiliki alternatif padanan yang lebih banyak di dalam bahasa penerima. Kenyataan ini juga membuktikan bahwa dalam penerjemahan, seorang penerjemah harus lebih menguasai bahasa penerima daripada bahasa sumber.

Tabel di atas juga menunjukkan bahwa masalah jumlah ('adad) yang terkandung dalam bahasa sumber dapat diungkapkan dalam bahasa penerima. Sebagai contoh pronomina persona turunan aranjeun dan maranéh tersusun dari pronomina persona kedua anjeun dan manéb dengan membubuhkan infiks -ar-sebagai pemarkah jamak. Di dalam kata aranjeun, posisi infiks -ar- yang lazim disisipkan di tengah-tengah kata berubah posisi menjadi di awal kata sebagai prefiks. 
Ara6iyât Jurnal Pendidikan Bahasa Arab dan Kebahasaaraban, 5 (1), 2018

Dengan demikian, terjemahan pronomina bahasa Sunda telah memenuhi aspek jumlah, yaitu, tunggal dan jamak, melalui proses morfologi afiksasi.

Walaupun aspek jumlah dapat dipenuhi oleh terjemahan, tampaknya aspek jender belum mampu dipenuhi. Pronomina bahasa Sunda bersifat netral, tidak menunjukkan kepada jenis kelamin laki-laki maupun perempuan. Hal ini dapat dipahami karena ada beberapa bahasa di dunia yang tidak memiliki perangkat linguistik penanda jender secara eksplisit, sedang bahasa lain memiliki perangkat itu secara eksplisit dan rinci. Tatkala kedua bahasa seperti ini terlibat penerjemahan, tentu saja konsep jender tidak dapat dipenuhi.

Temuan yang menarik pada tabel di atas ialah penerjemahan dhamir ana dan nabnu ke dalam kaula (orang pertama tunggal) dan kami (orang pertama jamak) secara bergantian, padahal dhamir ana merujuk pada orang pertama tunggal dan nabnu merujuk pada orang pertama jamak. Konteks ayat menjadi kunci pertukaran pemakaian kedua pronomina tersebut. Dalam konteks Allah dan Nabi Muhammad saw. sedang berbicara kepada makhluk atau umatnya, maka digunakan Kami untuk Tuhan atau kami untuk Nabi saw., padahal yang berbicara hanya seorang. Dalam bahasa Sunda, kata kami atau kaula pada umumnya digunakan dalam konteks pembicaraan antara majikan dengan pembantu, penguasa dengan rakyat, dan antara orang yang lebih tinggi kedudukannya kepada orang yang lebih rendah kedudukannya. Artinya, kata kaula dan kami hanya digunakan oleh orang yang memiliki power terhadap mitra tuturnya.

Tatkala Nabi Muhammad berbicara kepada umatnya, dhamir ana yang merujuk kepada beliau diterjemahkan dengan kaula guna menunjukkan posisi beliau yang lebih mulia, terhormat, berkuasa, dan terpandang daripada umatnya. Hal ini terlihat pada contoh berikut.

Naba aranjeun hayang dibejaan ku kaula kunu leuwih hade tibatan eta? (QS.3: 15).

He Abli Kitab! Hiap kadieu (urang pada nyekel) kalimah anu sarua antara kaula (umat Islam) jeung aranjeun... (QS.3:64)

Ketika Tuhan berbicara kepada orang kafir, dhamir ana yang merujuk kepada Allah Yang Maha Esa diterjemahkan dengan Kami seperti pada cntoh berikut,

He Isa! Satemenna Kami bakal mawa bidep kana abir ajal hidep, jeung bakal ngangkat bidep ka Kami... (QS.55)

Ari jalma-jalma kupur the bakeal disiksa ku Kami ku sikesaan anu pohara beuratna boh di dunya, boh di aberat (QS.3: 56).

Hal tersebut menunjukkan adanya ekuivalensi budaya antara bahasa Arab dan bahasa Sunda karena adanya budaya penghormatan kepada mitra tutur yang memiliki status sosial yang lebih tinggi atau yang memunyai kekuasaan (power) yang lebih besar.

Temuan di atas sejalan dengan pendapat Aziz yang mengemukakan hasil penelitian tentang kata ganti dalam Alquran dan kaitannya dengan status sosial, khususnya di kalangan masyarakat Mesir. Dia menegaskan bahwa berbagai tingkat 
sosial itu tercermin dalam berbagai bentuk bahasa, di antaranya dalam perubahan dhamîr dan bentuk-bentuk bahasa yang dikaitkan dengan perubahan dhamîr. ${ }^{15}$

Perubahan itu terjadi ketika penutur mengekspresikan status sosial, penghormatan, atau power-nya dalam dhamir bahasa Arab. Di samping pada dhamir, perubahan bentuk juga ditunjukkan melalui gaya bahasa dan pemilihan kosa kata (diksi).

Dalam penelitian tentang pemakaian dhamîr dalam Alquran, Aziz menyimpulkan bahwa Allah Ta'ala mengeskpresikan zat-Nya dengan dhamîr mutakallim mufrad (kata ganti orang pertama tunggal) atau dengan dhamîr mutakallim jamak (kata ganti orang pertama jamak). Namun, kata ganti jamak ini tidak dimaknai jamak, sebab Tuhan hanya satu, dhamir "jamak" itu perlu dimaknai sebagai mu'að̧̧̧һam nafsah (penanda kepemilikan power dan kemuliaan).

Tatkala orang-orang yang beriman menyapa Allah Ta'ala atau berdoa kepadaNya, maka kita melihat Alquran mengungkapkannya dengan dhamîr mukhathab mufrad (kata ganti orang kedua tunggal). Hal ini menunjukkan kenetralan dhamir dalam bahasa Arab. Artinya, anta dapat digunakan kepada siapa pun, termasuk kepada Tuhan. Namun, tatkala seorang muslim Sunda hendak mengungkapkan anta, dia merasa tidak sopan jika mengungkapkannya dengan maneh atau Anjeun. Karena itu, dia memilih kata Gusti, yang dianggapnya lebih sopan daripada kata Anjeun atau maneh. Jadi, dia beralih dari dhamir kepada nomina yang berarti Tuhan.

Aziz juga mengemukakan bahwa dalam perkembangan bahasa Arab ragam resmi, dewasa ini dikenal perubahan dari dhamîr mukhathab mufrad (anta) menjadi dhamîr mukhathab jama' (antum). Dhamir antum digunakan tatkala seseorang menyapa orang yang lebih mulia, terhormat, dan memiliki kedudukan yang lebih tinggi daripada pembicara. Sementara itu dhamîr anta digunakan dalam situasi akrab dan di antara orang yang memiliki kedudukan yang sama. Hal yang sama terjadi pula pada deiksis persona. $^{16}$

Tabel temuan di atas juga menunjukkan bahwa penerjemah telah mengindahkan budaya yang berlaku di kalangan penutur bahasa Sunda. Dalam budaya Sunda dikenal kesantunan yang ditunjukkan melalui pemakaian bahasa, khususnya kata ganti. Tatkala pronomina anta, antum, buwa, dan bum merujuk kepada orang yang berbeda keyakinan, orang yang tidak memiliki agama, atau orang yang dikenal menyalahi norma, maka pronomina itu diterjemahkan dengan maneh, manehna, maranehna sebagai ragam bahasa sedang dan wajar, bukan ragam bahasa halus, tetapi bukan pula ragam bahasa kasar. Sebaliknya, tatkala pronomina itu merujuk kepada orang Muslim, Nabi, atau orang saleh, maka pronomina itu diterjemahkan dengan bidep, anjeun, anjeunna, aranjeunna. Tatkala pronomina itu merujuk kepada Tuhan, Nabi, dan orang Muslim, maka diterjemahkan dengan Gusti, Mantenna, abdi, abdi sadaya.

${ }^{15}$ Muhammad Hasan Abdul Aziz, Tlmu Lughah al-Ijtima'I (Mesir: Maktabah al-Adab, 2009), 6970.

${ }^{16}$ Yael-Janette Zupnik. "A pragmatic analysis of the use of person deixis in political discourse". Journal of Pragmatics 21 (1994) 339-383. 
Temuan ini sejalan dengan pandangan Mammadov dan Rosmawati yang menyatakan bahwa kata ganti persona merupakan perangkat paling eksplisit untuk merepresentasikan kedudukan seseorang. ${ }^{17}$

Sesungguhnya, dalam bahasa Arab, pronomina tersebut bersifat netral dan egaliter, tidak mengandung unsur penghormatan atau kesantunan, kecuali pada dhamir orang pertama tunggal atau jamak. Pronomina buws, bum, biya, bunna, misalnya, dapat digunakan kepada Tuhan, Nabi, orang Muslim, orang tidak beragama, pelaku maksiat, dan siapa saja tanpa melihat atribut dan status sosial. Kemudian pronomina tersebut diterjemahkan ke dalam bahasa Sunda dengan mempertimbangkan unsur budaya bahasa penerima, yaitu aspek kesantunan, status sosial, perbedaan agama, perbedaan keyakinan, etika, dan moral. Pertimbangan yang sama juga terjadi pada deiksis dan metafora. ${ }^{18}$

Hal ini menunjukkan bahwa telah terjadi interaksi antara budaya Arab-Islam dengan budaya Sunda-Islam. Kegiatan saling mempengaruhi budaya ini disebut transkulturasi berupa peralihan bentuk dari budaya egaliter, netral, dan inklusif menjadi memihak, ekslusif, santun, dan komunikatif.

Gejala transformasi budaya dan masuknya pengaruh budaya Sunda ke dalam terjemahan, paling tidak dipengaruhi oleh dua hal. Pertama, pengaruh penggunaan metode komunikatif yang mementingkan budaya dan bahasa penerima serta mementingkan keterpahaman terjemahan bagi pembaca. Kedua, adanya intervensi penerjemah dalam proses penerjemahan, sebab penerjemahan itu merupakan proses kreatif, bahasa hanyalah alat ekspresi makna yang tunduk pada kehendak pemakainnya, dan setiap penerjemah memiliki minat dan kecenderungannya masing-masing dalam proses penerjemahan.

\section{Simpulan}

Sembilan jenis pronomina yang ada dalam data surah Ali Imran diterjemahkan ke dalam bahasa Sunda secara variatif. Variasi itu telah memenuhi konsep jumlah ('adad) melalui proses afiksasi. Namun, terjemahan belum mampu memenuhi aspek jender karena bahasa Sunda tidak memiliki perangkat morfologis penanda jender kecuali perangkat linguistik yang eksplisit. Penerjemahan pronomina tersebut

17 Azad Mammadov. "Deictic Representations Of Person In Media Discourse". Lodz Papers in Pragmatics 10.2 (2014): 245-259; Rosmawaty. "Analysis the Use of the Kind of Deixis on "Ayat-Ayat Cinta' Novel by Habiburrahman El Shirazy”. International Journal of Humanities and Social Science Vol. 3 No. 17, 2013, 57.

18 Mohamed Mazen Galal. "Death Euphemism in English and Arabic: A Conceptual Metaphorization Approach". International Journal of Linguistics. Vol. 6, 2014, No. 1; Yuanyuan Li. "A Social and Pragmatic Analysis of the Second Person Deixis You". Asian Social Science, Vol. 5, No.12, Desember 2009; Fatima Ahmad Al Aubali. "Deixis in Arabic and English: A Contrastive Approach". International Journal of Applied Linguistics \& English Literature. Vol. 4 No. 4, 2015. 
dilakukan dengan mempertimbangkan status sosial, strata sosial, dan hubungan sosial mitra tutur. Penerjemahan demikian ekuivalen dengan unsur penghormatan dalam budaya Arab-Islam. Penerjemahan juga dilakukan dengan mempertimbangkan agama, keyakinan, perilaku, moral, dan etika mitra tutur yang dirujuk oleh pronomina tersebut. Dalam konteks ini penerjemah telah memasukkan unsur budaya kesantunan ke dalam terjemahan, padahal unsur itu tidak dijumpai dalam bahasa sumbernya. Inilah bentuk transkulturasi dan transformasi dari budaya yang netral, egaliter, dan eksklusif dalam bahasa Arab menjadi budaya yang memihak, inklusif, santun, dan komunikatif dalam bahasa Sunda.[]

\section{DAFTAR RUJUKAN}

Abdelaal, Noureldin Mohammed. Semantic Loss in the Holy Qur'an Translation With Special Reference to Surah Al-Waqiah (Chapter of The Event Inevitable). SAGE and Open Access, 2015.

al-Aubali, Fatima Ahmad. "Deixis in Arabic and English: A Contrastive Approach". International Journal of Applied Linguistics \& English Literature. Vol. 4 No. 4, 2015.

Aziz, Muhammad Hasan Abdul. Tlmu Lughah al-Ijtima’i. Mesir: Maktabah al-Adab, 2009.

Aziz, Muhammed and Hendr, Ahmed. "Tranlation of Classical Arabic Language To English". Journal of Applied Sciences, Vol. 12 (8), 2012. pp. 781-786.

Babaee, Ruzbeh. and Yahya, Wan Roselezam Bt Wan Yahya. Creativity, Culture and Translation. English Language Teaching; Vol. 7, No. 6, 2014, p. 14-18.

Beypi, Serdihun and Biswas, Shiva. "Language, Culture, and Translation of the Karbi: A Brief Study". International Journal of Social Science and Humanity, Vol. 2, No. 6, 2012, pp. 8-15.

Blenkinsopp, John and Pajouh, Maryam Shademan. "Lost in translation? Culture, language and the role of the translator in international business". Critical Perspective on international business, Vol.6, No. 1, 2010, 38-52.

al-Farisi, Muhammad Zaka. Analisis Terjemahan Ayat-ayat Imperatif Alquran (Telaah Komparatif Terjemah Depag dan Terjemah UMT). Disertasi. Bandung: Sekolah Pascasarjana UPI, 2016.

Galal, Mohamed Mazen. "Death Euphemism in English and Arabic: A Conceptual Metaphorization Approach”. International Journal of Linguistics. Vol. 6, 2014, No. 1

Giovanni, Elena Di. “Translation, Culture, and The Media”. European Journal of English Studies, Vol. 12, No.2., 2008, pp.123-131.

al-Hamad, Mohammad Qasem, "The Translatability Of Euphemism In The Holy Quran”. European Scientific Journal January 2013 edition vol.9, No.2.

Hermawan, Acep. Penerjemahan Majaz Mursal dalam Alquran Terjemah Sunda Karya M.E. Hasim dan Pemda Jabar. Disertasi. Bandung: UIN Sunan Gunung Jati, 2015. 
Arabiyât Jurnal Pendidikan Bahasa Arab dan Kebahasaaraban, 5 (1), 2018

Li, Yuanyuan. "A Social and Pragmatic Analysis of the Second Person Deixis You". Asian Social Science, Vol. 5, No.12, Desember 2009.

Long, Lynne. (ed.). Translation and Religion: Holy Untranslatable? London: Multilingual Matters Ltd, 2005.

Lull, James. Media, Communication, Culture. New York. Columbia University, 2000.

Majeed, Nawfal Saeed. "A pragmatic Analysis of some polite Expressions in the Glorious Qura'n with References to their Realization in English". Tikrit University Journal for Humanities Vol. (16) No. (12) December (2009).

Mammadov, Azad. "Deictic Representations Of Person In Media Discourse". Lodz. Papers in Pragmatics 10.2 (2014): 245-259.

Mat, Azman Che. "Revisiting Arabic-Malay Translation Experience in Malaysia: A historical and Contemporary Account". Asian Culture and History, Vol.2, No.2, 2010, pp. 99-103.

Najjar, Ibrahim I.I. "A Contrastive Analysis of the Translation of Irony in the Holy Qur'an: The Translations of Mualawi Sher Ali and Yusuf Ali”. American Research Journal of English and Literature. Volume 1, Issue 5, 2015, p 27.

Nelson, Brian. "Translating Culture, Cultures of Translation". Journal of Intercultural Studies, Vol 28, No.4, 2007, pp. 361-365.

Newmark, Peter. A Textbook of Translation. United Kingdom: Prentice Hall International, 1988.

Nur, Tajudin. "Analisis Kontrastif dalam Studi Bahasa”, Arabi: Journal of Arabic Studies. Vol. 1 No. 2, 2016.

al-Rajhi, Ibrahim, Barlett, Dean, and Altman, Yochanna. "Research note: the development of an Arabic cross-cultural adjusment scale". Cross Cultural Management, Vol.20. No.3, 2013, pp. 449-463.

Rohmana, Jajan A. "Ideologisasi Tafsir Lokal Berbahasa Sunda: Kepentingan IslamModernis dalam Tafsir Nurul-Bajan dan Ayat Suci Lenyepaneun". Journal of Qur'an and Hadith Studies - Vol. 2, No. 1, 2013, 125-154.

Rosmawaty. "Analysis the Use of the Kind of Deixis on 'Ayat-Ayat Cinta' Novel by Habiburrahman El Shirazy". International Journal of Humanities and Social Science Vol. 3 No. 17, 2013, 57.

$\mathrm{Su}$, Yujie. "A Corpus-based Contrastive Analysis of First Personal Deixis".Journal of Language Teaching and Research, Vol. 1, No. 3, 2010, pp. 231-234.

Sudaryat, Yayat. Pronomina Persona dalam Bahasa Sunda. FPBS: Bandung, 2016.

Zsok, Izzabela. "The Culture of Translation: Texts and Practices". Philobiblon - Vol. 17, No. 1, 2012, pp. 307-312.

Zupnik, Yael-Janette. "A pragmatic analysis of the use of person deixis in political discourse". Journal of Pragmatics 21 (1994) 339-383. 